Hardy.- "Congenital aphakia," Ophthal. Record, Chicago, 1915, Vol. XXIV, p. 347.

Sherer._-"Congenital aphakia : a clinical report," Jl. Missouri Med. Assoc., St. Louis, I915, Vol. XII, p. 478.

Rabl. - "Ueber den Bau u. Entwicklung der Linse," Zeitschr. für wiss. Zool., Vol. LXIII, 1898 .

von Kupffer.-Verhandl. der Anatom. Gesellsch. auf der zehnten Versammlung in Berlin, 1896. (Becker's case.)

Wiegels, H.-Arch.f. Ophthal., Vol. L, 1900, p. 369.

Bach.- "Pathol. Anat. Studien ueber verschiedene Missbildungen des Auges." Arch. $f$. Ophth., Vol. XLV, Pt. I, p. I.

Ochi. - "Experimental study of histogenesis of eye abnormalities in chick embryos," Brit. Jl. Ophthal., 1919, Vol. III, p. 433.

Lewis, W. H. "Experimental study of development of Eye in Amphibia," Amer. Jl. Anat., Vol. III, I904, p. 505, and Vol. V, p. 9, 1906.

Spemann.-Anat. Anzeig., Vol. XIX, Suppl., p. 6I, I901.

\title{
THE YIELDING OF THE OPTIC NERVE-HEAD IN GLAUCOMA
}

\author{
BY
}

\author{
R. H. Elliot, Lt.-Col., I.M.S. (Retd.) \\ LONDON
}

IT is not an uncommon thing to find writers on glaucoma, making a casual reference to the possible influence on their subject of anatomical variations in the intraocular portion of the optic nerve, and in the canal which contains it. Such references are, however, for the most part so vague and indefinite as to provoke the suggestion that they are not founded on well-ascertained data. The writer has felt the need of greater precision in our knowledge of the subject, and this has been especially impressed upon him in connection with his study of the various paracentral scotomata which are met with in the glaucomatous. Of the various sources of information to which he is indebted, he would wish to make an early and special acknowledgment of two, viz., Salzmann's "Anatomy and Histology of the Human Eyeball" translated by Dr. E. V. L. Brown (University of Chicago Press, Chicago, 1912), and Fuchs' illuminating article "On the Lamina Cribrosa" (Arch.f. Ophthal., 1916, Vol. XCI, Part iii). The latter paper is by no means an easy one to study in the original, and this for various reasons, not the least of which is the arrangement therein followed. The writer desires to express his acknowledgments to Mr. E. E. Henderson for the help he has derived from that gentleman's lucid abstract of this voluminous paper (B.J.O. 1918, Vol. II, p. 50), and for the personal help he has given him in unravelling difficult details of the translation. It is in no sense derogatory to this abstract to say that, clear and helpful as it is, it was only by careful study of the original, and by putting together facts and statements in the order of sequence in which they affect the problems the writer had before him, that a clear view of the subject was obtained. Glaucoma teems 
with problems which demand and deserve very careful study. Such study cannot fail to add to our knowledge, and to help to dissipate the clouds which at present obscure our conception of this great subject. In the course of some work he had in hand, the writer had first to get his own ideas straightened out, so far as our present knowledge permits, and he has felt that having done so, his results may be helpful to others, as well as to himself.

\section{Anatomical Considerations}

It is essential, in the first place, to gain as clear a conception as is possible of the anatomical arrangements of the intraocular or bulbar portion of the optic nerve, of the canal in which it lies, and of the relationship of the nerve to the canal. The exact parts we are about to discuss will be understood, if we take a cleanly enucleated eye, with the optic nerve cut off flush with the scleral surface, and if we then make a study of the nerve and of the contiguous coats of the eye.

\section{The Entrance Canal of the Optic Nerve}

This is divided for anatomical purposes into a choroidal and a scleral portion. The inner or choroidal opening of the canal is

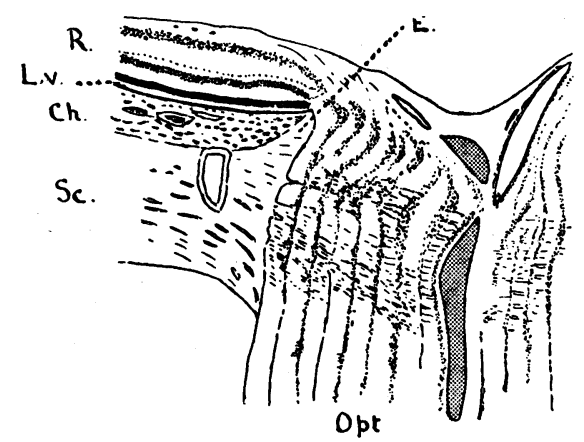

FIG. 1.-Semi-diagrammatic representation of lining of the canal of entrance of the optic nerve (modified from Salzmann). $\mathrm{R}$ retina, Ch choroid, L.v. lamina vitrea of choroid. The inturned selvedge-edge $E$ of the scleral tissue, which lines the choroidal part of the canal, ceases at the lamina vitrea. Sc sclera, Opt. optic nerve. (E.C.I.E.)

about $1.5 \mathrm{~mm}$. in width; it may be taken to be bounded by the margin of the opening in the choroid, and by the contiguous part of the sclera. The outer opening, or scleral foramen, as is wellknown, is usually much wider than the inner; its boundary is formed by the outmost layers of the sclera.

The wall of the canal is formed by a whitish fibrous tissue, which, in the choroidal part of the tube, is clearly distinguishable from the uveal layers, but which, in the sclerotic portion, blends with the adjacent sclera, with which it appears to be continuous. It is as 
though the sclera around the inner foramen ended in a selvedge edge, which is carried up clear to the membrane of Bruch; scleral tissue thus lines the whole of the optic canal (Fig. 1). There has been much dispute as to the exact nature of this lining, and for this reason Salzmann has preferred to describe it by the indefinite and non-committal name of "the border tissue." It is generally accepted that fibrous tissue elements from this border tissue extend into the framework of the optic nerve, and so help to form the cribriform plate. Differences of opinion exist (1) as to whether elements derived from the choroid take any part in the formation of the fibrous tissue framework of this part of the nerve, and (2) as to the exact part played by other tissues.

It is important to understand that the framework or scaffolding of this part of the nerve is derived from two sources: (1) the

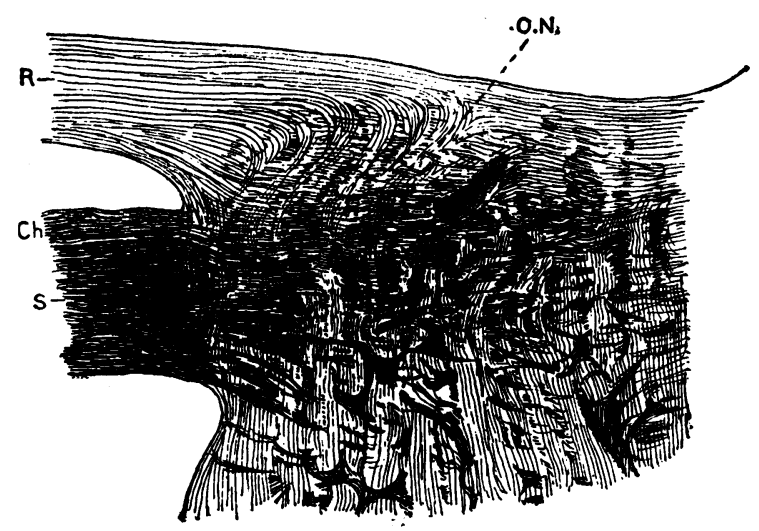

FIG. 3.-The transverse lamellae lie mainly in the anterior part of the optic canal, and are not very strong, as compared with the glial tissue which lies in bundles along the length of the nerve.

mesodermal, which we have just been discussing, and (2) the ectodermal. The latter tissue is usually spoken of as "neuroglia" or "glia." Considerable differences of opinion exist as to the exact relationships of these two sets of tissue within the intraocular portion of the optic nerve. Fuchs, who has recently conducted an exhaustive study of the subject, holds that there is a close interconnection between the connective tissue and the neuroglia. In spite (a) of their differences of origin, and (b) of the fact that staining reactions show that there are equally profound differences in their chemical nature, he finds that anatomically they are closely intermingled, and that the limits between them are not well defined. These views conflict with those of earlier writers. Such discussions are to a large extent academic. It is, however, of much greater and of more practical interest to note that the supporting tissue found in this portion of the nerve varies very greatly both in its 
distribution and in its amount. Thus, according to Fuchs, we find in some cases a tendency for a large amount of this tissue to lie in bundles along the direction of the length of the nerve, and so to run from before backwards, whilst in others it consists of sheets of laminae, which cross the nerve trunk at right angles to its course and which may and often do, run clean across all round from the marginal ring of the canal of the optic nerve to the central vessels. Moreover, these lamellae may vary in number, in strength and in completeness. These points are well illustrated by a comparison of Figs. 2, 3 and 4. In Fig. 2 it will be observed that the large number of strong lamellae, superposed upon each other, give the lamina cribrosa a considerable depth as measured from before backward, whilst in Figs. 3 and 4 the paucity of lamellae has diminished the depth of that membrane. Nor is this all that can be learnt from these illustrations. The strength of the individual lamellae, apart altogether from their numbers is obviously greater in

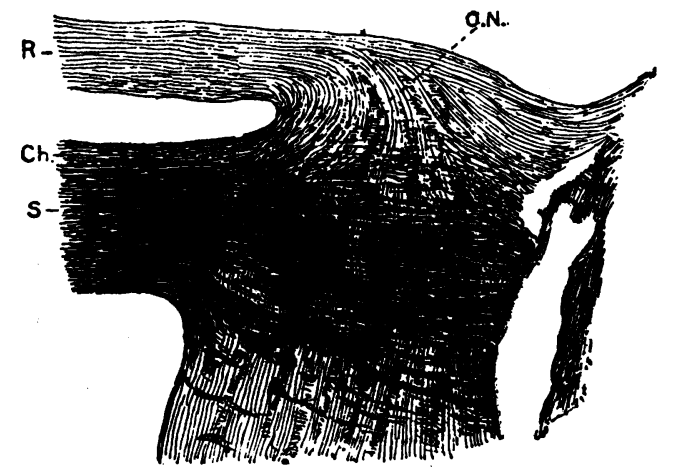

FIG. 2.-The transwerse lamellae are here very strong and are also very numerous. The result is that they build up a thick strong lamina cribrosa. The longitudinally placed glial elements are relatively poorly marked in this drawing.

the nerve depicted in Fig. 2 than in those of Figs. 3 and 4. Still one more point, the lamellae are not always of even strength right across the section of the nerve; indeed they appear to vary widely in this respect. If one may illustrate the point: In one case the membrane may be attached to the canal all round its circumference and may stretch across the whole section of the nerve ; in another, only a part of the membrane may be present, the remainder being wanting or weak. Granted then such differences in the number, thickness, and completeness of the individual lamellae, it must be at once obvious that not only will there be great differences in the resistance to pressure of the laminae cribrosae thus built up in different eyes, but also that similar differences will surely be found in different parts of this membrane, even in the same eye. Fuchs believes that those laminae cribrosae, whose elements are mainly 
made up of transversely running lamellae (Fig. 2) must be much more resistant to pressure applied, as intraocular pressure always must be, along the axis of the nerve, than are those in which the bulk of the tissue is built up of bundle-like elements, which run in the direction of the long axis of the nerve (Fig. 3). This proposition is selfevident, for the transverse lamellae, tethered as they are to the sides of the canal of the optic nerve, will check even the slightest tendency to a push of the nerve directly backwards, whilst the bundles, which run in the axis of the nerve, will readily be displaced, along with the structures between which they lie.

There is another point, of which we are not ignorant, but which has been emphasized for us by Fuchs in his paper under reference, viz., that the situation of the lamina cribrosa varies greatly in different

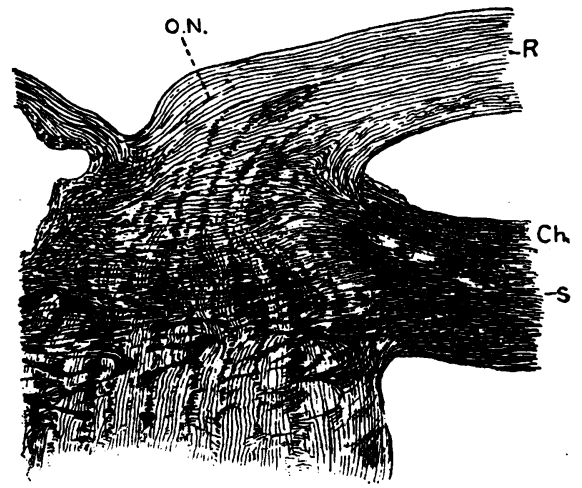

FIG. 4.-This resembles Fig. 3, except that the transverse lamellae lie mainly in the posterior part of the canal (the usua! arrangement) and the longitudinally placed glial bundles are not quite as strongly in evidence.

Fiss. 2, 3 and' 4 are diagrammatic representations, constructed from Fuchs' microphotographs, and modified in accordance with the text of his article to make the points he emphasizes clearer. They have been kindly supplied by the Oxford Medical Publications. The lettering is the same in all. $\mathrm{R}$, retina; $\mathrm{Ch}$. choroid; S, sclera; O.N., optic nerve.

eyes. This of course depends (1) on the position at which the various connective tissue lamellae, which between them, form the lamina, find their attachment to the walls of the optic canal and (2) on the number of these lamellae. Figures 2, 3 and 4 illustrate this point clearly. For convenience sake, we shall take them in reverse order. In Fig. 4, the lamina cribrosa lies in what is usually described as its normal position, i.e., in the posterior segment of the canal. In Fig. 3 it lies almost wholly in the anterior portion of the canal. Figure 2 forms a contrast with both of the preceding ones, since in it the lamina appears to occupy practically the whole length of the canal.

It is obvious, as Fuchs has pointed out, that these variations in anatomical structure must greatly influence the ophthalmoscopic 
appearances presented by different cases of optic atrophy, unaccompanied by increase of pressure; in the first case taken above (Fig. 4), the cup would be much deeper than in either of the others (Figs. 2 and 3), that is, if we assume that the underpressed anterior surface of the lamina cribrosa forms the floor of the cup.

Even under conditions in which pressure plays a part, the effect on the lamina is not quite so simple, according to Fuchs, as we have always been led to suppose. In the earlier stages, the whole of this supporting framework is not affected; for it is the glial tissue which yields first to pressure and disappears, whilst the connective tissue lamellae of mesodermal origin are still able to hold their ground. It is the glial fibres in the anterior part of the nerve head which are first destroyed, and their destruction, according to Fuchs, actually precedes that of the nerve fibres themselves. Later still, the glial elements of the whole framework of the intraocular portion of the nerve disappear. All these changes may occur before any displacement of the lamina cribrosa is in evidence. If, however, intraocular pressure is continued, the lamina yields as a whole, being pushed back into the optic nerve trunk, which is thereby proportionally shortened, and at the same time made thicker. Part of this thickening is due to changes in the nerve fibres, and to the development within the nerve of a condition which resembles a profuse oedema. Later, when atrophy is established, the nerve becomes thinner than before.

It remains to state, in support of what has been put forward above, that Fuchs has notes of four cases, in which the sectioned papillae showed depressions of their surfaces varying from 0.45 to $0.73 \mathrm{~mm}$. ; in none of these cases was the lamina markedly displaced, the cupping being due to destruction of the glial tissue and of the nerve substance. It is both noteworthy and strange that no evidence could be discovered in these cases of any increase, either in the strength or thickness of the lamina, such as might explain its remaining in position; indeed, in some of them, it appeared to be thinner than normal.

The sequence of events would appear to be as follows: (1) The disappearance of the delicate anterior glial fibres; (2) the disappearance of the deeper glial fibres incorporated in the lamina, or their fusion under pressure with the connective tissue lamellae; (3) the bending backward of the connective tissue lamellae, which build up the lamina; (4) the compression, sclerosis and even thickening of the lamina probably as a result of the load it has to bear ; and finally (5) the thinning and atrophy of the lamina as a result of continued pressure; at this stage, not only do the individual fibres become thinned and even disappear, but also a formation of spaces occurs, the lamina being thus increasingly broken up. 
Side by side with these changes in the supporting framework of the intraocular portion of the nerve, we have to take account of what is happening to the nerve fibres themselves. This is the more necessary because the course of events appears to differ widely in different cases, even so far as the nerve elements themselves are concerned. Thus, we may find extensive atrophy of the nervous tissues at a stage when only the anterior glial fibres have disappeared, and when the connective tissue lamellae, and consequently the lamina which they build up, are still in a normal position. Under such circumstances, as Fuchs points out, the picture presented might be that of an increased physiological cup with nerve atrophy. We have but to remember how deep the connective tissue lamellae may lie from the surface of the papilla in certain cases, and to cast our minds back for a moment to Fuchs' observation of cups up to nearly $0.75 \mathrm{~mm}$. in depth occurring under these conditions, to realize how difficult the ophthalmoscopic diagnosis of the exact condition present may easily become. On the other hand, in some cases, the lamina may yield at an early stage, whilst the nerve fibres are still intact. From the point of view of the symptoms presented, the cases will vary greatly. On the one hand, there may be comparatively shallow cupping with marked atrophy and early loss of vision; on the other, deep cupping with very moderate atrophy and comparatively little impairment, either of central or peripheral sight.

If we may accept Fuchs' work-as there is every reason to believe we may, not only on account of its author's reputation, but also because it falls into line with our clinical experience of increased intraocular pressure, with all its variations in the signs and symptoms present-we are bound to agree with its author that the problem of glaucoma is not the simple one of the physical effects of pressure alone. No one who has studied the congeries of conditions which we classify under the term "glaucoma" can fail to be convinced of the depth of our ignorance on the subject we are discussing. This admission, however, implies neither sympathy nor agreement with the views that sometimes find expression in medical literature, to the effect that the symptoms of glaucoma are independent of a rise in intraocular pressure. Such an idea is little likely to be accepted by anyone who has studied the subject and who takes broad, balanced views of the situation. Unfortunately, the study of glaucoma has, perhaps more than any other domain of ophthalmology, been invaded by theories, which have had little to recommend them, and which have only served to add confusion to the subject. Fortunately, their influence has generally been ephemeral, though it can hardly be said to have been harmless.

There are many departments of the study of glaucoma, which will 
be illumined by advances in our knowledge of the anatomical peculiarities that may be met with in the intraocular portion of the optic nerve and of the canal in which it lies, as well as of the relationships of the one to the other. Mr. A. Hugh Thompson read before the Oxford Ophthalmological Congress of July, 1920, an extremely interesting paper on "Physiological and Glaucoma Cups," pointing out how difficult it is in certain cases to draw a clear boundary line between physiological and pathological cupping. More recently, Mr. R. Pickard has taken up the same theme in a paper presented to the Royal Society of Medicine on January 14, 1921. Both these communications deal with the subject from the clinical point of view, and it is to be hoped and anticipated that they will stimulate others to carry the work still further. It is obvious that the most hopeful line of progress will lie in a combination of clinical and pathological investigations, for we cannot interpret aright what we see with the ophthalmoscope unless we check and simplify it by what we learn in the pathological laboratory.

Again, much interest has centred in recent years on the information furnished to the student of glaucoma by the results of careful perimetry and scotometry. Roenne's step, Seidel's sign, Bjerrum's sign and the jagged scotoma to which attention has been drawn by the writer, probably all find their explanation in (1) injuries to the nerve bundles as they pass over the edge of the disc, and (2) interference with the circulatory supply of the injured fibres in particular, and with that of the retina at large. How is the injury inflicted? Why should one mass of fibres-those, for instance, that emerge from a definite and circumscribed area above or 'below the disc-be more injured than any others? Why should we find the characteristic scotoma of glaucoma continuous as a rule with the blind spot, whilst exceptionally, but by no means rarely, the paracentral scotoma observed may be separated from that spot by large areas of clear vision? Why should the ophthalmoscopic picture of the glaucoma cup vary so very widely in the overhanging of the scleral edge, and in the kinking of the vessels, not only in different cups, but also in different sectors of the same cup? Why should the scleral edge of the inner foramen as seen in microscopic sections, seem at times so much sharper than at others, carrying with this peculiarity the suggestion that its power for harm, alike on the nerve fibres that flow over it, and on the vessels which accompany them, varies greatly in different cases? Are we here dealing with variations in the normal distribution of the retinal nerve fibres? Or, have we to do with uneven yielding of one or another of the two elements of the connective tissue that makes up the lamina? Or, is it a question of that direct pressure on the nerve fibres themselves to which Fuchs has drawn attention in this valuable paper? Or, must we explain the phenomena by a combination of all these influences? 
Finally, is there in glaucoma some dark sinister factor which pathology has so far failed to grasp, some nameless, hitherto shadowy, influence for evil, whose detection has evaded all the means at our disposal ?

These are very difficult questions, but not less attractive and important on that account. Nothing will do more to hinder the advance of our knowledge of glaucoma than the assumption that we really understand the subject, and probably nothing will be more likely to lead to progress than a candid exposure of the depth of our ignorance. For these reasons the writer does not hesitate to ask such questions as the above without making any serious attempt for the present to provide an answer to them.

\section{SLOUGHING CORNEA IN GRAVES'S DISEASE AND IN DISSEMINATED SCLEROSIS}

BY

\section{T. HARRISON BUtLER}

LEAMINGTON SPA.

ARNOLD KNAPP contributed to the Archives of Ophthalmology for March, 1918, a paper upon the loss of the cornea in Graves's disease. This catastrophe is not, he says, so very uncommon, and he recounts a case in which he succeeded in saving useful vision in one eye. In the following case first one cornea and then the other sloughed away, and ultimately the patient died.

On February 7, 1918, Mrs. P., aged 40, was sent to consult me by Dr. Bury, of Leamington Spa, who had tried every known treatment to relieve the symptoms of an aggravated case of exophthalmic goitre. On examination, in addition to all the usual signs of the disease, I found that there was an exaggerated proptosis of each globe, so much indeed that, when the eyes were closed as much as possible the left cornea was exposed. I strongly advised Mrs. P. to let me suture the left lids together. She was unwilling to follow this advice, and I did not see her again till March 2, 1918, when I examined her in bed at her own home. I found intense chemosis and brawny swelling of the conjunctiva of both eyes: the proptosis was even more pronounced : and the left cornea was infiltrated in its lower quadrant, and was anaesthetic. The tension of both eyes appeared to be raised, but there was nothing in their appearance to suggest glaucoma. I concluded that the apparent hardness was due to the tense state of the tissues behind the eye. Subsequent examination with the Schiötz tonometer showed that the tension was 20. I admitted Mrs. P. to the Warneford Hospital, where we instilled atropin, and carefully bandaged the eye. On March 3 a definite ulcer had formed in the 